\title{
Compositions, flavour and antiradical properties of products from subcritical water treatment of raw Isada krill
}

\section{AUTHOR(S):}

Koomyart, Intira; Nagamizu, Hironori; Khuwijitjaru, Pramote; Kobayashi, Takashi; Shiga, Hirokazu; Yoshii, Hidefumi; Adachi, Shuji

\section{CITATION:}

Koomyart, Intira ...[et al]. Compositions, flavour and antiradical properties of products from subcritical water treatment of raw Isada krill. International Journal of Food Science \& Technology 2015, 50(7): 1632-1639

\section{ISSUE DATE:}

2015-03-03

URL:

http://hdl.handle.net/2433/201904

\section{RIGHT:}

This is the peer reviewed version of the following article: Koomyart, I., Nagamizu, H., Khuwijitjaru, P., Kobayashi, T., Shiga, H., Yoshii, H. and Adachi, S. (2015), Compositions, flavour and antiradical properties of products from subcritical water treatment of raw Isada krill. International Journal of Food Science \& Technology, 50: 1632-1639, which has been published in final form at http://dx.doi.org/10.1111/ijfs.12799. This article may be used for non-commercial purposes in accordance with Wiley Terms and Conditions for Self-Archiving.; The full-text file will be made open to the public on 3 March 2016 in accordance with publisher's 'Terms and Conditions for Self-Archiving',; この論文は出版社版でありませ ん。引用の際には出版社版をご確認ご利用ください。; This is not the published version. Please cite only the published version. 


\section{Compositions, flavor and antiradical properties of products from subcritical water treatment of raw Isada krill}

Intira Koomyart ${ }^{1}$, Hironori Nagamizu ${ }^{1}$, Pramote Khuwijitjaru ${ }^{2}$, Takashi Kobayashi ${ }^{1}$, Hirokazu Shiga ${ }^{3}$, Hidefumi Yoshii ${ }^{3}$, and Shuji Adachi, ${ }^{1{ }^{*}}$

${ }^{1}$ Division of Food Science and Biotechnology, Graduate School of Agriculture, Kyoto University, Sakyo-ku, Kyoto 606-8502, Japan

${ }^{2}$ Department of Food Technology, Faculty of Engineering and Industrial Technology, Silpakorn University, Nakhon Pathom 73000, Thailand

${ }^{3}$ Department of Applied Biological Science, Faculty of Agriculture, Kagawa University, Miki-cho, Kita-gun, Kagawa 761-0795, Japan

*Corresponding author: Shuji Adachi

Tel.: +81-75-753-6286; Fax: +81-75-753-6285

E-mail address: adachi@kais.kyoto-u.ac.jp

Keywords: Isada krill (Euphausia pacifica), Subcritical water, Flavor evaluation, Antiradical activity

\section{Summary}

Comparative analysis of subcritical water (SCW) treatment and ambient pressure boiling one of raw Isada krill was performed for the nutritive, flavor, and antiradical properties of krill extracts and residues as well as the molecular mass and odor intensity of the extract. SCW treatment was performed for $10 \mathrm{~min}$ in a batch-type vessel in the temperature range of $100-240^{\circ} \mathrm{C}$, using a $1: 1$ weight ratio of raw krill to water. Higher protein and lipid contents were obtained by SCW treatment relative to boiling. The lipid content of the SCW extracts increased with increasing treatment temperature. Protein was the main component in these extracts, and the highest protein content was achieved by SCW treatment at $200^{\circ} \mathrm{C}$. High-molecular-mass species decomposed under SCW treatment at high temperatures with consequent generation of smaller molecules. The antiradical activity of the SCW extract, determined by DPPH and ABTS assays, increased with increasing treatment temperature. The krill extracts and residues exhibited shrimp-like flavor and the most desirable preference flavor was obtained by SCW treatment at $140^{\circ} \mathrm{C}$ or $160^{\circ} \mathrm{C}$ for $10 \mathrm{~min}$. The treatment would be applicable for production of seasonings from Isada krill.

\section{Introduction}

Isada krill (Euphausia pacifica) is a small crustacean found mainly on the Sanriku coast of Japan. Most of Isada krill is used in animal feed and aquaculture. After harvesting, the quality of the krill rapidly deteriorates due to reactions by endogenous enzymes (Kawamura et al., 1981). Because of development of bad smell and color, the krill is not utilized extensively for human consumption despite a widely available food resource with high in nutritional value of protein, beneficial lipids (e.g., polyunsaturated fatty acids such as eicosapentaenoic and docosahexaenoic acids), and bioactive compounds (e.g., astaxanthin and vitamin E) (Tou et al., 2007). The biomass of Isada krill is abundant, but its annual harvest is only about 40 thousand tons because of its restricted usage. However, much attention has been paid on use of krill for human diet and its beneficial fatty acids (Cripps et al., 1999), isolated proteins (Chen et al., 2009), and amino acids (Ali-Nehari et al., 2011) were characterized.

The shrimp-like flavor of krill is widely used as a savory flavor enhancer in food products, including seafood sauce, soup, and surimi (Kim et al., 2010). Identification and characterization of the volatile components of shrimp have been undertaken in numerous studies. For example, Morita et al. (2001) identified 2-acetyl-1-pyroline and 2-acetylthaiazole as active volatile compounds in boiled prawn, whereas Tachihara et al. (2004) found that pyrazines, e.g., 2,5-dimethylpyrazine and 3,5-dimethylpyrazine, are developed through the 
Maillard reaction in roasted shrimp. Kim et al. (2010) developed the cooked-shrimp flavor from the enzymatic hydrolysate of shrimp by the Maillard reaction. Kubota et al. (1986) extracted and concentrated the shrimp-like flavor of roasted shrimp by distillation. However, few studies have focused on utilizing subcritical water (SCW) extraction for producing extracts rich in shrimp-like flavor.

$\mathrm{SCW}$ (pressurized hot water or compressed hot water) remains in the liquid state at temperatures of $100^{\circ} \mathrm{C}$ to $374^{\circ} \mathrm{C}$ under pressurized conditions. The increased temperature of SCW results in a higher diffusion coefficient and lower dielectric constant, density, and viscosity (Toor et al., 2011) relative to water boiled at ambient pressure. SCW has been used as a medium for extracting valuable compounds from marine materials, such as scallop (Tavakoli and Yoshida, 2006), squid (Uddin et al., 2010; Yoshida and Tavakoli, 2004; Kim et al., 2013), and defatted krill (Ali-Nehari et al., 2011). Recently, we demonstrated that treatment of semi-dried krill with SCW can produce extracts and solid residues that provide a pleasant flavor and may prospectively be used as seasoning ingredients (Koomyart et al., 2015). In addition, the extract would be a good source of substances with antioxidant activity (Kim et al., 2013). To extend the knowledge base for utilizing SCW treatment for producing shrimp-flavored ingredients, raw krill is used as a starting material in this study and the antiradical activity of the products is evaluated.

\section{Materials and methods}

\section{Materials}

Isada krill frozen and packed in a 1-kg plastic shrink wrap was purchased from Hamaichi (Wakayama, Japan) and stored in a freezer at $-30^{\circ} \mathrm{C}$ until use. The average mass and length of the krill were $0.07 \pm 0.01 \mathrm{~g}$ and $18.00 \pm 0.65 \mathrm{~mm}$, respectively. Diethyl ether, Folin-Ciocalteu reagent, trisodium citrate dihydrate, copper (II) sulfate pentahydrate, bovine serum albumin (BSA), 1,1-diphenyl-2-picryl-hydrazyl (DPPH), 2,2'-azinobis(3-ethylbenzothaiazoline-6-sulfuric acid) (ABTS), 6-hydroxy-2,5,7,8tetramethylchroman-2-carboxylic acid (Trolox), and potassium persulfate, and uracil were purchased from Wako Pure Chemical Industries (Osaka, Japan). Myoglobin, tri -tyrosine, di-L-phenylalanine, and L-phenylalanyl-L-alanine dihydrate were purchased from Sigma-Aldrich (Tokyo, Japan). Glucose oxidase was purchased from Nacalai Tesque (Kyoto, Japan). Other reagents were of analytical grade.

\section{Subcritical water and boiling treatment}

For SCW treatment, the pack of frozen krill was thawed in the pack using tap water and $30 \mathrm{~g}$ of the thawed krill was mixed with $30 \mathrm{~g}$ of distilled water. The mixture was poured into a $117 \mathrm{~mL}$ batch-type vessel (Taiatsu Techno, Osaka, Japan). The closed vessel was then heated with a temperature-controlled ribbon heater (200W, As One, Osaka, Japan) to a desired temperature in a range of $100-240^{\circ} \mathrm{C}$. After reaching the desired temperature, the system was maintained at that temperature for $10 \mathrm{~min}$, after which the vessel was immediately cooled by immersion in ice water.

For the ambient pressure boiling (APB) treatment, $90 \mathrm{~g}$ of the thawed krill was mixed with $90 \mathrm{~g}$ of distilled water and boiled at atmospheric pressure in an open aluminum pot for $10 \mathrm{~min}$.

The solid residue and liquid extract were separated by filtering the mixture through a No. 2 Advantec filter paper under vacuum. The solid residue was then transferred to a Teflon mesh bag (MS-150 Moku, $144 \mu \mathrm{m}$ mesh opening, $25 \times 100 \mathrm{~mm}$, Semitec, Tokyo, Japan) and was further pressed by a hydraulic machine at 7.86 MPa; the obtained liquid was then combined with the liquid krill extract.

All of the treatments were conducted in triplicate.

\section{Total solid content of krill extract}

The total solid content of the krill extract was determined by a hot-air drying method according to ISO method 6496 (ISO, 1999). One gram of the krill extract in an aluminum cup was dried in a hot-air oven at $135^{\circ} \mathrm{C}$ for $2 \mathrm{~h}$. After drying, the cup was immediately placed in a desiccator for $15 \mathrm{~min}$ and weighed. The solid content is reported as $\mathrm{kg} / \mathrm{kg}$-extract.

\section{Crude oil content of krill extract and residue}

The crude oil content of krill was determined using the solvent extraction method (AOAC, 2006). The krill 
residue was dried in a hot-air oven at $105^{\circ} \mathrm{C}$ for $4 \mathrm{~h}$ and crushed into powder, while the extract $(1 \mathrm{~g})$ was dehydrated with sodium sulfate $(2 \mathrm{~g})$. The dried krill residue powder $(1 \mathrm{~g})$ or dehydrated extract was placed in an extract thimble and set in a Soxhlet extractor. Extraction was performed over $10 \mathrm{~h}$ using diethyl ether at $47.5^{\circ} \mathrm{C}$. The remaining solvent in the extracted oil was removed by evaporation. The residual oil was weighed and expressed as $\mathrm{kg} / \mathrm{kg}$-raw krill.

\section{Protein content}

The Lowry-Folin method was employed to determine the total protein content of the krill extract (Lowry et al., 1951). The krill extract $(10 \mathrm{~mL})$ was centrifuged at $6000 \mathrm{rpm}(4270 \times \mathrm{g})$ for $20 \mathrm{~min}$ at $4^{\circ} \mathrm{C}$. A standard curve was prepared using BSA solutions with concentrations ranging from 100 to $500 \mathrm{mg} / \mathrm{L}$. The diluted supernatant or BSA solution $(0.4 \mathrm{~mL})$ was mixed with Lowry reagent $(2 \mathrm{~mL})$ and $50 \%(\mathrm{w} / \mathrm{v})$ Folin-Ciocalteu reagent $(0.2$ $\mathrm{mL}$ ). The absorbance of the mixture was measured at $750 \mathrm{~nm}$ using a UV-1600 spectrophotometer (Shimadzu, Kyoto, Japan).

\section{Freezing point depression}

The freezing point depression, $\Delta T_{\mathrm{f}}\left({ }^{\circ} \mathrm{C}\right)$, was measured as an indicator of the overall molality of the extract using an osmometer (OM802, Vogel, Kevelaer, Germany) (Koomyart et al., 2015), and the molecular mass of solutes $\left(M_{\text {solute }}\right)$ in the extract was roughly estimated using Eq. (1).

$$
M_{\text {solute }}=m_{\text {solute }} K_{\mathrm{f}} / \Delta T_{\mathrm{f}}
$$

where $m_{\text {solute }}$ is the total solid content $(\mathrm{g} / \mathrm{kg})$ and $K_{\mathrm{f}}$ is the molal freezing point depression constant of water $(1.86$ $\left.{ }^{\circ} \mathrm{C} \cdot \mathrm{kg} / \mathrm{mol}\right)$.

\section{Size exclusion chromatography}

Size exclusion chromatography was performed by using an HPLC system comprising an LC-10AD pump and an RID-10A refractive index detector (Shimadzu, Kyoto, Japan). The krill extract was centrifuged at $6000 \mathrm{rpm}$ for $20 \mathrm{~min}$ and filtered through a $0.45 \mu \mathrm{m}$ syringe filter (PTFE, Advantec, Osaka, Japan); $20 \mu \mathrm{L}$ of the filtered sample was injected onto a YMC-Pack Diol-120 column $(500 \times 8.0 \mathrm{~mm}$ i.d., YMC, Kyoto, Japan $)$, which is applicable to molecules with molecular masses of 10,000 to several hundred thousand (YMC General catalogue 2007/2008, YMC, Kyoto, Japan). Distilled water was used as the mobile phase (flow rate: $1.0 \mathrm{~mL} / \mathrm{min}$ ). The mass distribution in the extract was determined using the external molecular mass standards comprising glucose oxidase (153 kDa), BSA (66 kDa), myoglobin (16.9 kDa), Tyr-Tyr-Tyr (507 Da), Phe-Phe (312 Da) and uracil (112 Da) dissolved in distilled water.

\section{Odor intensity}

To measure the odor intensity, $1 \mathrm{~mL}$ of the extract or $1 \mathrm{~g}$ of the residue was placed into a $10 \mathrm{~mL}$ glass bottle. The bottle was then capped and incubated in a water bath at $25^{\circ} \mathrm{C}$ for $10 \mathrm{~min}$. The odor intensity in the head space was measured by using an odor concentration meter (XP-329IIIR, Cosmos, Tokyo, Japan). The odor intensity is expressed as odor units $/ \mathrm{mL}$ of head space $(\mathrm{ou} / \mathrm{mL})$.

\section{Flavor preference evaluation}

The flavor preference of the krill extract and residue was determined by sensory evaluation. The krill extract (1 $\mathrm{mL})$ or the wet residue $(1 \mathrm{~g})$ was placed in an amber glass bottle at room temperature and presented to 10 sensory panelists who were instructed to perform preference scoring using the 5-point hedonic scale (-2: dislike extremely, -1 : dislike, 0 : neither like nor dislike, +1 : like, and +2: like extremely).

\section{Antiradical activity analyses}

DPPH assay

The DPPH radical scavenging activity of the krill extract was determined as described by Faithong et al. (2010) with slight modifications. The extract was centrifuged at $6000 \mathrm{rpm}$ for $5 \mathrm{~min}$ and diluted with distilled water. Trolox was dissolved and serially diluted with $95 \%$ ethanol to concentrations in the range of 5-50 $\mu \mathrm{mol} / \mathrm{L}$. Subsequently, $1.5 \mathrm{~mL}$ of the diluted extract, $95 \%$ ethanol (control) or Trolox solution were combined with 1.5 $\mathrm{mL}$ of $0.15 \mathrm{mmol} / \mathrm{L} \mathrm{DPPH}$ in $95 \%$ ethanol. The mixture was vortex-mixed and kept in the dark at ambient 
temperature for $30 \mathrm{~min}$. The absorbance of the mixture was measured at $517 \mathrm{~nm}$ using a UV 1600 spectrophotometer (Shimadzu, Kyoto, Japan). The DPPH radical scavenging activity was calculated using Eq. (2):

$$
\text { Scavenging activity }(\%)=100 \times\left(A_{\text {control }}-A_{\text {sample }}\right) / A_{\text {control }}
$$

where $A_{\text {control }}$ and $A_{\text {sample }}$ are the absorbance of the mixture of DPPH and $95 \%$ ethanol and the sample, respectively.

The percentage DPPH radical scavenging activity of the sample was compared with that of Trolox in order to express the DPPH radical scavenging activity as $\mu \mathrm{mol}$ Trolox equivalent (TE)/g-extract.

$$
\mathrm{TE}=C_{\text {Trolox }} / W_{\text {extract }}
$$

where $C_{\text {Trolox }}$ is the Trolox equivalent concentration of the extract $(\mu \mathrm{mol} / \mathrm{mL})$ and $W_{\text {extract }}$ is weight of the extract (g).

\section{ABTS assay}

The ABTS assay was conducted as described by Arnao et al. (2001) with slight modifications. A stock solution of ABTS radical was prepared by mixing $7.4 \mathrm{mmol} / \mathrm{L} \mathrm{ABTS}$ solution and $2.6 \mathrm{mmol} / \mathrm{L}$ potassium persulfate solution (1:1 by volume); the mixture was allowed to react for $12 \mathrm{~h}$ at ambient temperature in the dark. The solution was then diluted by mixing $1 \mathrm{~mL}$ of the solution with $50 \mathrm{~mL}$ of methanol. The sample $(150 \mu \mathrm{L})$ was mixed with $2850 \mu \mathrm{L}$ of freshly prepared ABTS solution. The mixture was kept at room temperature for $2 \mathrm{~h}$ and the absorbance of the mixture was spectrophotometrically determined at $734 \mathrm{~nm}$. A standard curve for Trolox was prepared in the $100-500 \mu \mathrm{mol} / \mathrm{mL}$ concentration range.

The ABTS radical scavenging activity was calculated and expressed as $\mu$ mol Trolox equivalent (TE)/g-extract based on Eqs. (2) and (3), respectively.

\section{Statistical analysis}

Statistical analysis of experimental data was performed by analysis of variance (ANOVA) using SPSS 17 (IBM, NY, USA) program and indicated as means \pm standard deviation. The least significant difference test (LSD) for complete randomized design (CRD) was performed to determine the significant difference among the means of treatments at $p=0.05$. For sensory evaluation, the randomized complete block design (RCBD) was conducted for preference score at the same level.

\section{Results and discussion}

\section{Yield of krill extract and residue}

Two fractions (the liquid krill extract and solid krill residue) were obtained from APB and SCW treatments of raw krill followed by hydraulic pressing. The visual appearance of the extract and residue obtained by APB and SCW treatments at various temperatures is shown in Fig. 1. Light yellow extracts were obtained from the APB and SCW treatments at $100-140^{\circ} \mathrm{C}$, whereas the residues were pink and retained the krill appearance. Dark brown extracts were obtained with the use of higher temperatures $\left(160-240^{\circ} \mathrm{C}\right)$ and the residues were gray and lost the krill appearance completely.

The yields of the extract and residue obtained by APB were $0.55 \mathrm{~kg}$-extract $/ \mathrm{kg}$-mixture and $0.16 \mathrm{~kg}$-wet residue/kg-mixture, respectively. APB in an open container permitted evaporation of water and thus resulted in considerable loss of the extract. For the SCW treatment, the yield of the residue decreased whereas the yield of the extract increased with increasing treatment temperature. Drastic changes in the yield of the extract and residue from SCW treatment were observed at $140-200^{\circ} \mathrm{C}$ (Fig. 2). The corresponding, respective decline and rise in the yield of the residue and extract demonstrated that krill extraction with SCW was more efficacious at higher temperatures.

\section{Protein, lipid, and solid contents}

Protein was the major component in the krill extract obtained by SCW treatment. A gradual increase in the protein content from 0.018 to $0.038 \mathrm{~kg} / \mathrm{kg}$-extract $(45.7-65.0 \%$ of total solid) was observed as the treatment temperature increased from 100 to $200^{\circ} \mathrm{C}$; however, no further increase in the protein content of the extract was achieved with the use of higher temperatures (Fig. 3(a)). This observation is consistent with that of our previous 
report (Koomyart et al., 2015). The increase in the protein content of the SCW extracts is an indication of hydrolysis of proteinaceous components in the krill to soluble peptides and amino acids (Yoshida et al. 1999).

The lipid content of the krill extract and residue is defined as the weight of lipid produced from $1 \mathrm{~kg}$ of raw krill (Fig. 3(a)). The lipid content of the extract prepared by SCW treatment at $100^{\circ} \mathrm{C}$ did not differ from that obtained by APB; however, the lipid content of the SCW extract gradually increased from 0.0039 to 0.0225 $\mathrm{kg} / \mathrm{kg}$-raw krill with an increase in the temperature from 120 to $240^{\circ} \mathrm{C}$. The dissolution of lipophilic substances is enhanced by the lowered polarity, surface tension, and viscosity of SCW (Khuwijitjaru et al., 2002), which facilitates extraction of nonpolar components (Pourali et al., 2009) at high temperature, thereby accounting for the observed increase in the lipid content of the SCW extract with increasing temperature. However, residual lipid was detected in the residues (28.7-67.6\% of total lipid), indicating that complete lipid extraction could not be achieved with $\mathrm{SCW}$ at the evaluated temperatures.

The solid content of the SCW extracts increased from 0.04 to $0.06 \mathrm{~kg} / \mathrm{kg}$-extract with increasing treatment temperature (Fig. 3(b)). Due to evaporation of water during treatment in the open container at $100^{\circ} \mathrm{C}$, the freezing point depression of this extract was notably larger than that of the extract obtained using the closed vessel. The freezing point depression of the extracts obtained at $100-180^{\circ} \mathrm{C}$ were almost the same; however, $T_{\mathrm{f}}$ of the extract obtained at $240^{\circ} \mathrm{C}$ was higher than that of the extract obtained at $220^{\circ} \mathrm{C}$ despite the similarity of the solid content of these extracts. Thus, it can be inferred that the components of the krill were hydrolyzed to soluble components at higher temperatures.

\section{Molecular mass distribution}

The molecular mass distribution of the extracts was qualitatively determined using SEC (Fig. 4(a)). Three groups of peaks, i.e., high $\left(>10^{5} \mathrm{Da}\right)$, moderate $\left(10^{3}-10^{5} \mathrm{Da}\right)$, and low $\left(<10^{3} \mathrm{Da}\right)$ molecular-mass peaks, were observed in the typical chromatogram. Only minor differences were observed in the moderate-molecular mass profiles of the extracts obtained using $\mathrm{APB}$ and $\mathrm{SCW}$ at $100^{\circ} \mathrm{C}$.

At temperatures in the range of $100-140^{\circ} \mathrm{C}$, the extracts obtained using SCW treatment all had similar patterns and signal heights. For the samples subjected to $\mathrm{SCW}$ treatment at $160-180^{\circ} \mathrm{C}$, the intensity of the peaks corresponding to high- and moderate-molecular mass species was greatly enhanced and low-molecular-mass species were also detected with SCW treatment at these temperatures. Certain peaks corresponding to high-molecular-mass species disappeared with $\mathrm{SCW}$ treatment at $240^{\circ} \mathrm{C}$ and the intensity of the low-molecular-mass peaks also declined to some extent at this temperature. These results are consistent with those of previous reports (Wiboonsirikul et al., 2007; Uddin et al., 2010). Wiboonsirikul et al. (2007) reported that SCW treatment resulted in an increase in the content of low and high molecular-mass components in protein extracts from defatted rice bran with an increase in the temperature from 50 to $200^{\circ} \mathrm{C}$, but caused a decrease at $250^{\circ} \mathrm{C}$. Uddin et al. (2010) also found that the protein yield from SCW hydrolysis of raw squid viscera decreased when the temperature was increased from 200 to $280^{\circ} \mathrm{C}$. The decrease in the content of the high- and low-molecular-mass substances at $240^{\circ} \mathrm{C}$ may be ascribed to the decomposition of these molecules by SCW. The decomposition of protein and amino acids under hydrothermal conditions generates small and volatile components, i.e., organic acids and volatile compounds (Yoshida et al., 1999).

Figure 4(b) shows the molecular mass of solute in the extracts; the molecular mass was estimated from the freezing point depression using Eq. (1). The highest molecular mass of the solutes in the extract was obtained by SCW treatment at $180^{\circ} \mathrm{C}$. The gradual decrease in the estimated molecular mass with increasing temperature agreed well with the previously described decline in the peak height of the high-molecular mass components in the chromatograms at the corresponding temperatures. Because protein was the main component found in the hydrolysates, it is possible that SCW treatment at high temperature promoted the formation of lower-molecular mass substances due to protein hydrolysis. For instance, Mekonnen et al. (2014) reported that the subcritical hydrolysis of proteins from waste proteinaceous biomass produced a narrower molecular weight distribution and smaller molecules at higher degrees of hydrolysis.

\section{Odor intensity and flavor preference}

Flavor plays an important role in food product acceptance. The odor intensity and flavor preference of the extracts and residues were determined to evaluate the effect of the subcritical treatment temperature on these parameters as indicators of product acceptance. Figure 5 shows the odor intensities detected by a 
semi-conductor sensor. The odor intensities of the extracts and residues from both treatments increased with increasing treatment temperature. Generally, during thermal treatment of a material containing protein and carbohydrate, many compounds such as aromatic compounds, alcohols, and ketones are developed through the Maillard reaction (van Boekel, 2006). Because these products are volatile and water-soluble, the odor intensity of the extract is higher than that of the residue.

The preference test by panelists is important for selection of desirable products for use as food ingredients. Kubota et al. (1986) found that pyrazines (i.e., 5-dimethylpyrazine, 2,3,5-trimethylpyrazine, and 2-ethyl-6-methylpyrazine) were important constituents of the cooked-shrimp flavor in the extract of cooked shrimp. The desirable flavor of cooked shrimp was also generated by SCW treatment of Isada krill. The highest scores of overall flavor were assigned to the extract and residue obtained by SCW treatment at 140 and $160^{\circ} \mathrm{C}$, respectively. The detection of a fishy odor for the extracts from APB and SCW treatments at $100^{\circ} \mathrm{C}$ may have led to the low scores of these samples. The low scores of the extracts and residues from treatment at more severe temperatures $\left(180-240^{\circ} \mathrm{C}\right)$ due to the detection of burnt odor. Cooking at elevated temperature led to the development of overheating products of the Maillard reaction, i.e. alkylpyridine and furans (van Boekel, 2006), which resulted in the detection of an off-flavor. Therefore, the extract and residue obtained by SCW treatment at 140 and $160^{\circ} \mathrm{C}$, respectively, are considered to be prospective candidates for use as seasonings with shrimp-like flavor.

\section{Antiradical activities}

Figure 6 shows the antioxidant activities of the extracts obtained from the APB and SCW treatments. The DPPH and ABTS radical scavenging activities of the extract obtained by SCW treatment ranged from 38.35-62.92 and 193.32-469.35 $\mu \mathrm{mol} \mathrm{TE} / \mathrm{g}$-extract, respectively. The extracts prepared at higher temperatures exhibited higher DPPH and ABTS radical scavenging activities. It has been reported that the hydrolysates of shrimp, krill, and marine materials possess antioxidant activity (Faithong et al., 2010). The antiradical activity of the extract depended on the degree of protein hydrolysis and the amount of protein hydrolysate (Thiansilakul et al., 2007). In addition, Maillard reaction products may also act as antioxidants (Naknean and Bancheun, 2013). Plaza et al. (2010) reported that increasing the SCW extraction temperature from 100 to $200^{\circ} \mathrm{C}$ increased the antioxidant capacity of brown algae (U. pinnatifida) extract.

\section{Conclusions}

SCW treatment of raw Isada krill produced promising products for use as shrimp-flavored seasoning ingredients with functionalities. Its indications, i.e., protein, solid and lipid contents, and antiradical activity of these products, increased with the use of higher treatment temperatures. SCW treatment at high temperatures $\left(\geq 180^{\circ} \mathrm{C}\right)$ promoted the hydrolysis of high-molecular-mass substances. However, the most desirable shrimp-like flavor was obtained from the 1:1 (w/w) mixture of raw krill and water by SCW treatment at 140 and $160^{\circ} \mathrm{C}$. Eventually, the knowledge presented in this study extend a method for using the krill as a starting material for seasoning with shrimp-like flavor that would increase the value of the krill as a food resource for human diet.

\section{Acknowledgments}

This project was supported by The Creation of Innovative Technology for Marine Products Industry, Program for Revitalization Promotion, Japan Science and Technology Agency (JST).

\section{References}

Ali-Nehari, A., Kim, S. B., Lee, Y. B. \& Chun, B. S. (2011). Production of value added materials by subcritical water hydrolysis from krill residues extracted by supercritical carbon dioxide. Africa Journal of Biotechnology, 10, 18450-18457.

AOAC (2006). Official methods of analysis of AOAC International. AOAC International, 18th edn., Gaithersburg, MD.

Arnao, M. B., Cano, A. \& Acosta, M. (2001). The hydrophilic and lipophilic contribution to total antioxidant 
activity. Food Chemistry, 73, 239-244.

Chen, Y.-C., Tou, J. \& Jaczynski, J. (2009). Amino acid and mineral composition of protein and other components and their recovery yields from whole Antarctic krill (Euphausia superba) using isoelectric solubilization/precipitation. Journal of Food Science, 74, 31-39.

Cripps, G. C., Watkins, J. L., Hill, H. T. \& Atkinson, A. (1999). Fatty acid content of Antarctic krill Euphausia superba at South Georgia related to regional populations in diet. Marine Progress Series, 181, 177-188.

Faithong, N., Benjakul, S., Phatcharat, S. \& Binsan, W. (2010). Chemical composition and antioxidative activity of the traditional fermented shrimp and krill products. Food Chemistry, 199, 133-140.

ISO (1999). ISO 6496:1999 Animal feeding stuffs-Determination of moisture and other volatile matter content. International Organization for Standardization. Geneva, Switzerland.

Kawamura, Y., Nishimura, K., Igarashi, S., Doi, E. \& Yonezawa, D. (1981). Characterstics of autolysis of Antarctic krill. Agricultural and Biological Chemistry, 45, 93-100.

Khuwijitjaru, P., Adachi, S. \& Matsuno, R. (2002). Solubility of saturated fatty acids in water at elevated temperatures. Bioscience Biotechnology Biochemistry, 66, 1723-1726.

Kim, M. C., Oh, J. H., Kim, B. Y., Cho, S. M., Lee, D. S., Nam, M. H., Lee, Y. B. \& Kim, S. B. (2010). Development of boiled-type shrimp flavor by Maillard reaction and sensory evaluation. Journal of Food Science and Nutrition, 15, 304-308.

Kim, R. H., Asaduzzaman, A. K. M., You, C. H. \& Chun, B. S. (2013). Stability of antioxidant properties and essential amino acids in squid viscera hydrolysate produced using subcritical water. Fisheries and Aquatic Sciences, 16, 71-78.

Koomyart, I., Nagamizu, H., Khuwijitjaru, P., Kobayashi, T., Shiga, H., Yoshii, H. \& Adachi, S. (2015). Subcritical water treatment for producing seasoning from semidried Isada krill. Journal of Food Process Engineering, 37, 567-574.

Kubota, K., Shijimaya, H. \& Kobayashi, A. (1986). Volatile components of roasted shrimp. Agricultural and Biological Chemistry, 50, 2867-2873.

Lowry, O. H., Rosebrough, N. J., Lewis, F. A. \& Randall, R. J. (1951). Protein measurement with the Folin phenol reagent. Journal of Biological Chemistry, 193, 265-275.

Mekonnen, T. H., Mussone, P. G., El-Thaer, N., Choi, P. \& Bressler, D. C. (2014). Subcritical hydrolysis and characterization of waste proteinaceous biomass for value added applications. Journal of Chemical Technology and Biotechnology, in press, doi: 10.1002/jctb.4333.

Morita, K., Kubota, K. \& Aishima, T. (2001). Sensory characteristics and volatile components in aromas of boiled prawns prepared according to experimental designs. Food Research International, 34, 473-481.

Naknean, P. \& Banchuen, J. (2013). Characteristics and antioxidant activity of Maillard reaction products derived from chitosan-sugar solution. International Food Research Journal, 20, 1077-1085.

Plaza, M., Amigo-Benavent, M., Castillo, M. D., Ibáñez, E. \& Herrero, M. (2010). Facts about the formation of new antioxidants in natural samples after subcritical water extraction. Food Research International, 43, 1123-1129.

Pourali, O., Asghari, F. S. \& Yoshida, H. (2009). Sub-critical water treatment of rice bran to produce valuable materials: A review. Food Chemistry, 155, 1-7.

Tachihara, T., Ishizaki, S., Ishikawa, M. \& Kitahara, T. (2004). Studies on the volatile compounds of roasted spotted shrimp. Chemistry and Biodiversity, 1, 2024-2033.

Tavakoli, O. \& Yoshida, H. (2006). Conversion of scallop viscera wastes to valuable compounds using sub-critical water. Green Chemistry, 8, 100-106.

Thiansilakul, Y., Benjakul, S. \& Shahidi, F. (2007). Antioxidative activity of proteins hydrolysate from round scad muscle using alcalase and flavourzyme. Journal of Food Biochemistry, 31, 266-287.

Toor, S. S., Rosendahl, L. \& Rudolf, A. (2011). Hydrothermal liquefaction of biomass: A review of subcritical water technologies. Energy, 36, 2328-2342.

Tou, J. C., Jaczynski, J. \& Chen, Y. (2007). Krill for human consumption: nutritional value and potential health benefits. Nutrition Reviews, 65, 63-77.

Uddin, M. S., Ahn, H., Kishimura, H. \& Chun, B. (2010). Production of valued materials from squid viscera by subcritical water hydrolysis. Journal of Environmental Biology, 31, 675-679.

van Boekel, M. A. J. S. (2006). Formation of flavor compounds in the Maillard reaction. Biotechnology 
Advances, 24, 230-233.

Wiboonsilikul, J., Kimura, Y., Kadota, M., Morita, H., Tsuno, T. \& Adachi, S. (2007). Properties of extracts from defatted rice bran by its subcritical water treatment. Journal of Agricultural and Food Chemistry, 55, 8759-8765.

Yoshida, H. \& Tavakoli, O. (2004). Subcritical water hydrolysis treatment for waste squid entrails and production of amino acids, organic acids, and fatty acids. Journal of Chemical Engineering of Japan, 37, 253-260.

Yoshida, H., Terashima, M. \& Takahashi, Y. (1999). Production of organic acids and amino acids from fish meat by sub-critical water hydrolysis. Biotechnology Progress, 15, 1090-1094.

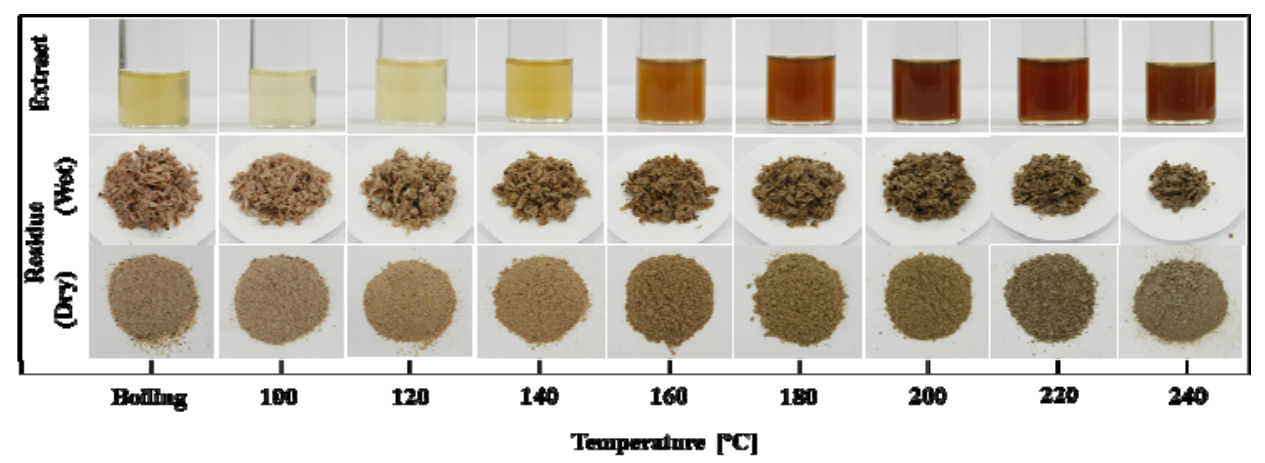

Fig. 1 - Krill extracts and residues obtained by ambient pressure boiling at $100^{\circ} \mathrm{C}$ and subcritical water treatments at various temperatures for $10 \mathrm{~min}$. Dry residues were obtained by hot-air drying $\left(70^{\circ} \mathrm{C}\right.$ for $\left.4 \mathrm{~h}\right)$ followed by grinding.

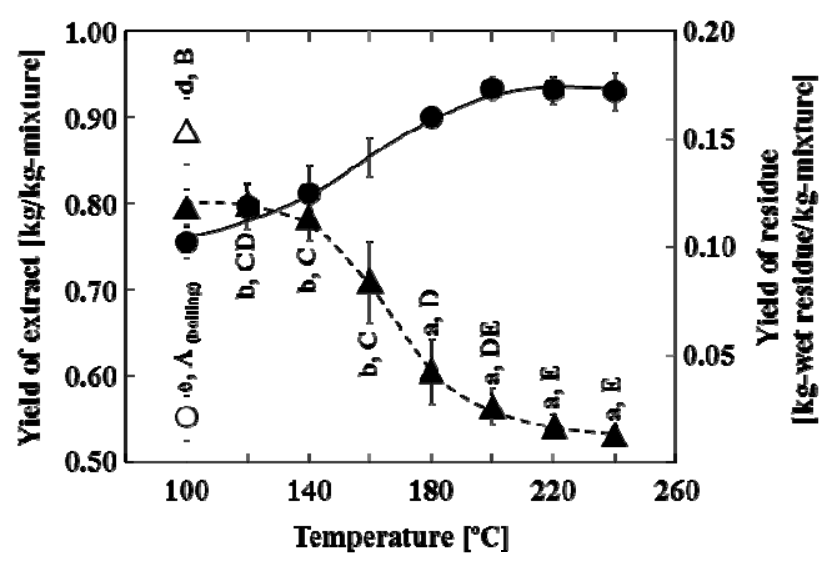

Fig. 2 - Yields of krill extract $(\boldsymbol{\bullet}, \bigcirc)$ and residue $(\boldsymbol{\Lambda}, \triangle)$ obtained by ambient pressure boiling (open symbols) and subcritical water treatments at various temperatures (closed symbols).

Capital and small letters indicate significant differences $(p<0.05)$ for the residue and extract, respectively. 


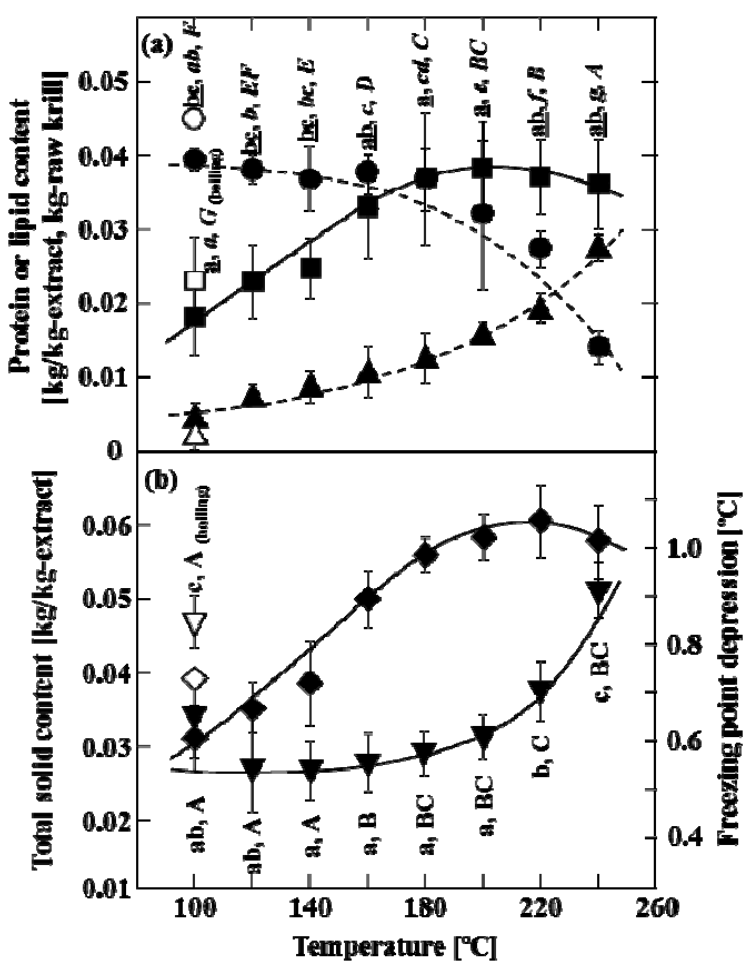

Fig. 3 - Lipid content of extract $(\boldsymbol{\Delta}, \triangle)$ and residue $(\boldsymbol{O}, \bigcirc)$ and protein content of the extracts $(\square$, $\mathbf{\square})$ (a) and total solid content $(\diamond, \diamond)$ and freezing point depression $(\boldsymbol{\nabla}, \nabla)$ of krill extract (b) obtained by ambient pressure boiling (open symbols) and subcritical water treatment at various temperatures (closed symbols).

Underlined small letters, upright capital and small letters, and slant capital and small letters indicate significant differences $(p<0.05)$ for the protein content, freezing point depression, solid content, and lipid content in the residue and extract, respectively.
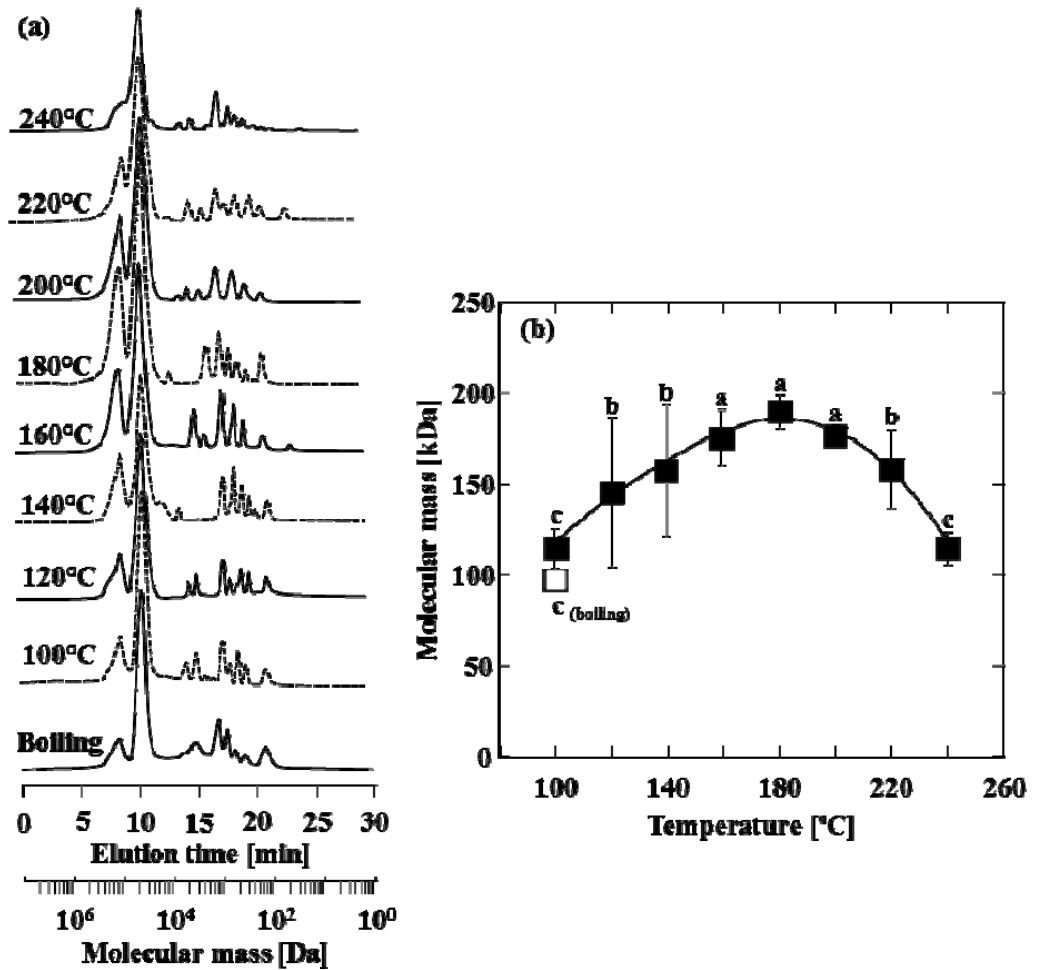

Fig. 4 - Size exclusion chromatograms (a) and treatment-temperature dependence of the molecular mass estimated from the freezing point depression and solid mass (b) of krill extracts obtained by ambient pressure boiling (open symbol) and subcritical water treatment at various temperatures (closed symbols).

The letters indicate significant differences $(p<0.05)$. 


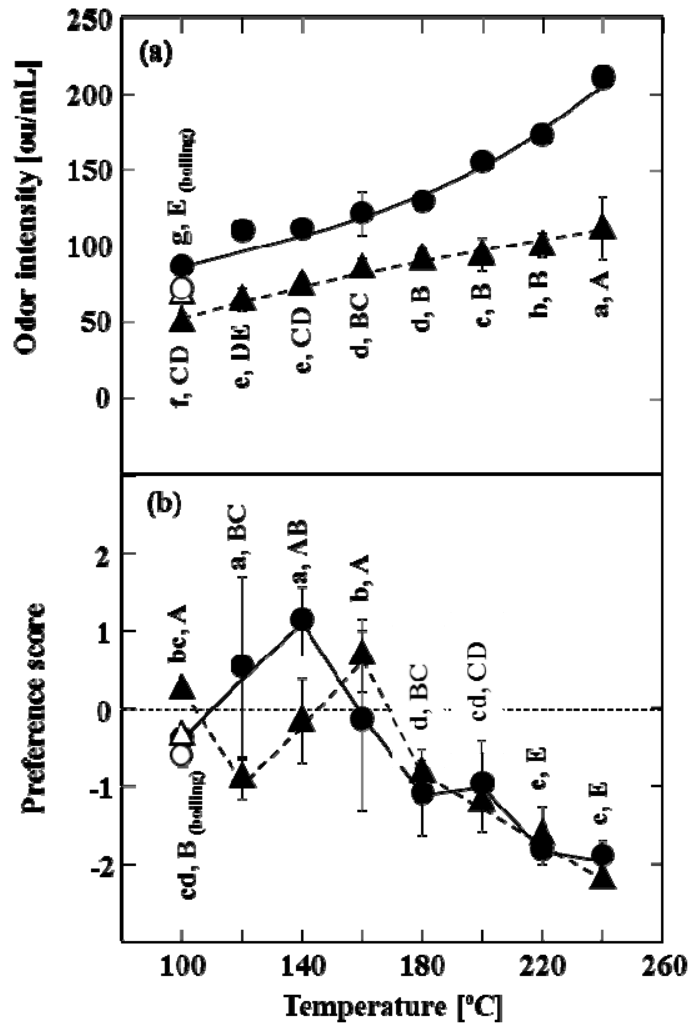

Fig. 5 - Odor intensity (a) and preference score of overall flavor (b) from krill extract $(\boldsymbol{\bullet}, \bigcirc)$ and residue $(\boldsymbol{\Lambda}$, $\triangle$ ) obtained by ambient pressure boiling (open symbols) and subcritical water treatment at various temperatures (closed symbols).

Capital and small letters indicate significant differences $(p<0.05)$ for the residue and extract, respectively.

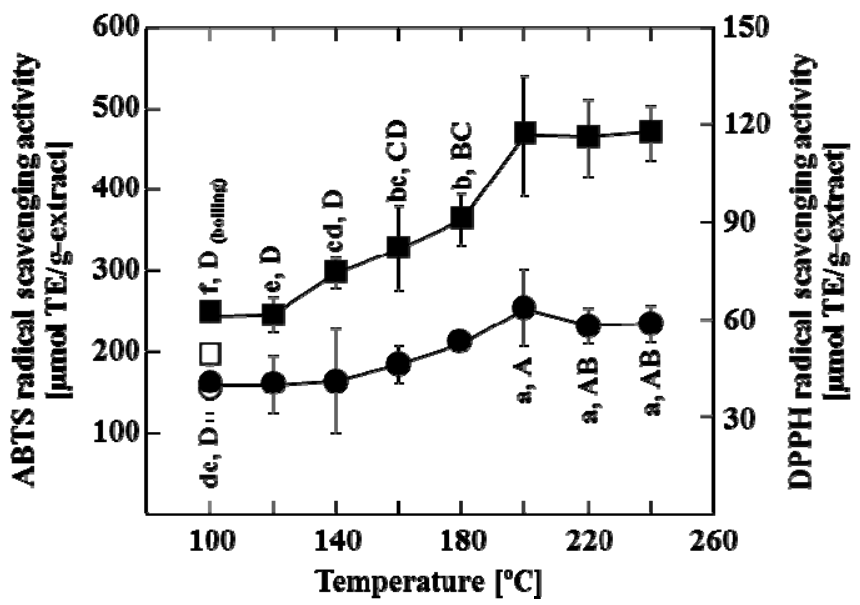

Fig. 6 - DPPH $(\bullet, O)$ and ABTS $(\boldsymbol{\square}, \square)$ radical scavenging activities of krill extracts obtained by ambient pressure boiling (open symbols) and subcritical water treatment at various temperatures (closed symbols). Capital and small letters indicate significant differences $(p<0.05)$ for the DPPH and ABTS, respectively. 